\title{
Rapid Synapse Elimination after Postsynaptic Protein Synthesis Inhibition In Vivo
}

\author{
Corey M. McCann, ${ }^{\star}$ Quyen T. Nguyen, ${ }^{\star}$ Humberto Santo Neto, and Jeff W. Lichtman \\ Department of Molecular and Cellular Biology, Harvard University, Cambridge, Massachusetts 02138
}

To examine the role of retrograde signals on synaptic maintenance, we inhibited protein synthesis in individual postsynaptic cells in vivo while monitoring presynaptic terminals. Within $12 \mathrm{~h}$, axon terminals begin to atrophy and withdraw from normal postsynaptic sites. Structural similarities between this process and naturally occurring synapse elimination suggest that short-lived target derived factors not only participate in synaptic maintenance in adults, but also regulate elimination of connections during development.

Key words: synaptic maintenance; trophic factors; neuromuscular junction; time lapse; synapse elimination; protein synthesis

\section{Introduction}

A number of lines of evidence suggest that presynaptic nerve terminals and postsynaptic target cells signal to each other as they establish precisely aligned synaptic specializations (Sanes and Lichtman, 2001). Less is known, however, about the ways in which these synaptic structures are maintained. Experimental data support the idea that retrograde signaling occurs at synapses (Tao and Poo, 2001). It is also known that the overexpression of postsynaptic signals can lead to sprouting and facilitation of presynaptic inputs (Nguyen et al., 1998; Sigrist et al., 2000). However, it is not known whether target-derived factors are continuously required to maintain normal synapses. We examined the possibility that postsynaptic cells provide signals that maintain synapses by observing the consequences of protein synthesis inhibition in postsynaptic muscle fibers in living mice.

\section{Materials and Methods}

Intracellular injection of sternomastoid muscle fibers in vivo. Adult mice $(20-25 \mathrm{~g})$ were anesthetized and the sternomastoid muscle exposed as described previously (Lichtman et al., 1987). Superficial neuromuscular junctions (NMJs) were labeled and identified depending on the experiment with Rhodamine conjugated $\alpha$ bungarotoxin (TRITC-BTX; $5 \mu \mathrm{M}$; Invitrogen, Eugene, OR), cyan fluorescent protein, or yellow fluorescent protein (YFP) (Feng et al., 2000). A microelectrode (Femtotips; Eppendorf, Westbury, NY) filled with a mixture of intracellular injection solution (155 mm K-aspartic acid, 5.5 mм EGTA, 5.5 mm HEPES, pH 7.4), $0.6-2.0 \%$ tetramethylrhodamine or fluorescein isothiocyanate dextran as fluorescent tracer, with or without luffin $(40-300 \mu \mathrm{g} / \mathrm{ml}$; Sigma, St. Louis, MO), or saporin ( $300 \mu \mathrm{g} / \mathrm{ml}$; Sigma) was positioned near a junction under epillumination using a long working distance $40 \times$ waterimmersion objective ( 0.8 numerical aperture; Olympus, Tokyo, Japan).

Received Feb. 12, 2007; revised April 6, 2007; accepted April 24, 2007.

We thank the Lichtman laboratory for thoughtful reading of this manuscript.

*C.M.M. and Q.T.N. contributed equally to this work.

Correspondence should be addressed to Jeff W. Lichtman at the above address.

Q. T. Nguyen's present address: Division of Head and Neck Surgery, University of California, San Diego, San Diego, CA 92103.

H. Santo Neto's present address: Department de Anatomia Institudo de Biologica Unicamp, Campinas, Sao Paolo 13083-970, Brazil.

DOI:10.1523/JNEUROSCI.0627-07.2007

Copyright $\odot 2007$ Society for Neuroscience $\quad$ 0270-6474/07/276064-04\$15.00/0
Perfusion of lactated Ringer's (Baxter, Deerfield, IL) solution across the surface of the muscle was adjusted so that any of the injection solution leaking from the microelectrode did not accumulate. The tip of the electrode was then advanced to pierce the plasma membrane of the muscle fiber of interest 10-15 $\mu \mathrm{m}$ away from the endplate using a micromanipulator (Narishige, East Meadow, NY). A small quantity (200-2000 pl) of the injection solution was then pressure injected into the fiber.

Verification of protein synthesis blockade. On the day of injection, acetylcholine receptors (AChRs) present in the membrane of superficial NMJs were saturated with either (1) TRITC-BTX or (2) unconjugated BTX (5 $\mu \mathrm{M}, 45 \mathrm{~min})$. Three days after injection, the presence of newly inserted AChRs was tested by incubating the entire muscle in (1) Alexa647 BTX if the initial saturation was done with TRITC-BTX or (2) TRITC-BTX if the initial saturation was done with unlabeled BTX. In cases were unconjugated BTX was used to saturate previously inserted AChRs, YFP axon terminals were used to identify and relocate neuromuscular junctions.

Quantification of protein synthesis blockade. To determine the extent of protein synthesis inhibition, the amount of AChR insertion after blockade was assayed by calculating the ratio of AChRs labeled with a saturating dose of Alexa647 BTX at the time of injection to AChRs labeled with Oregon Green 514 BTX immediately before imaging. This ratio was calculated for saporin-injected and neighboring uninjected muscle fibers. Presynaptic occupancy for each junction was then calculated by dividing the area of BTX-labeled AChRs overlain by axon by the total AChR area.

To assess the spatial extent of protein synthesis inhibition, dystrophin was labeled using mAb1808 (Roche Diagnostics, Mannheim, Germany) followed by a Cy3-conjugated goat-anti-mouse secondary antibody (Jackson ImmunoResearch, West Grove, PA) (Culican et al., 1998). Highresolution confocal images of superficial muscle fibers were taken using the same microscope settings and the intensities of different regions were compared using MetaMorph software (Universal Imaging, Downingtown, PA).

Schwann cell labeling. Schwann cells were labeled in a transgenic mouse line expressing green fluorescent protein under control of the S100 promoter (Zuo et al., 2004). To simultaneously image Schwann cells and presynaptic axons, these mice were crossed to mice expressing cyan fluorescent protein in motor neurons (Feng et al., 2000).

\section{Results}

Protein synthesis inhibition at individual postsynaptic sites in vivo

Postsynaptic protein synthesis inhibition (PoPSIn) was accomplished by intracellular injection of a small amount of a ribo- 


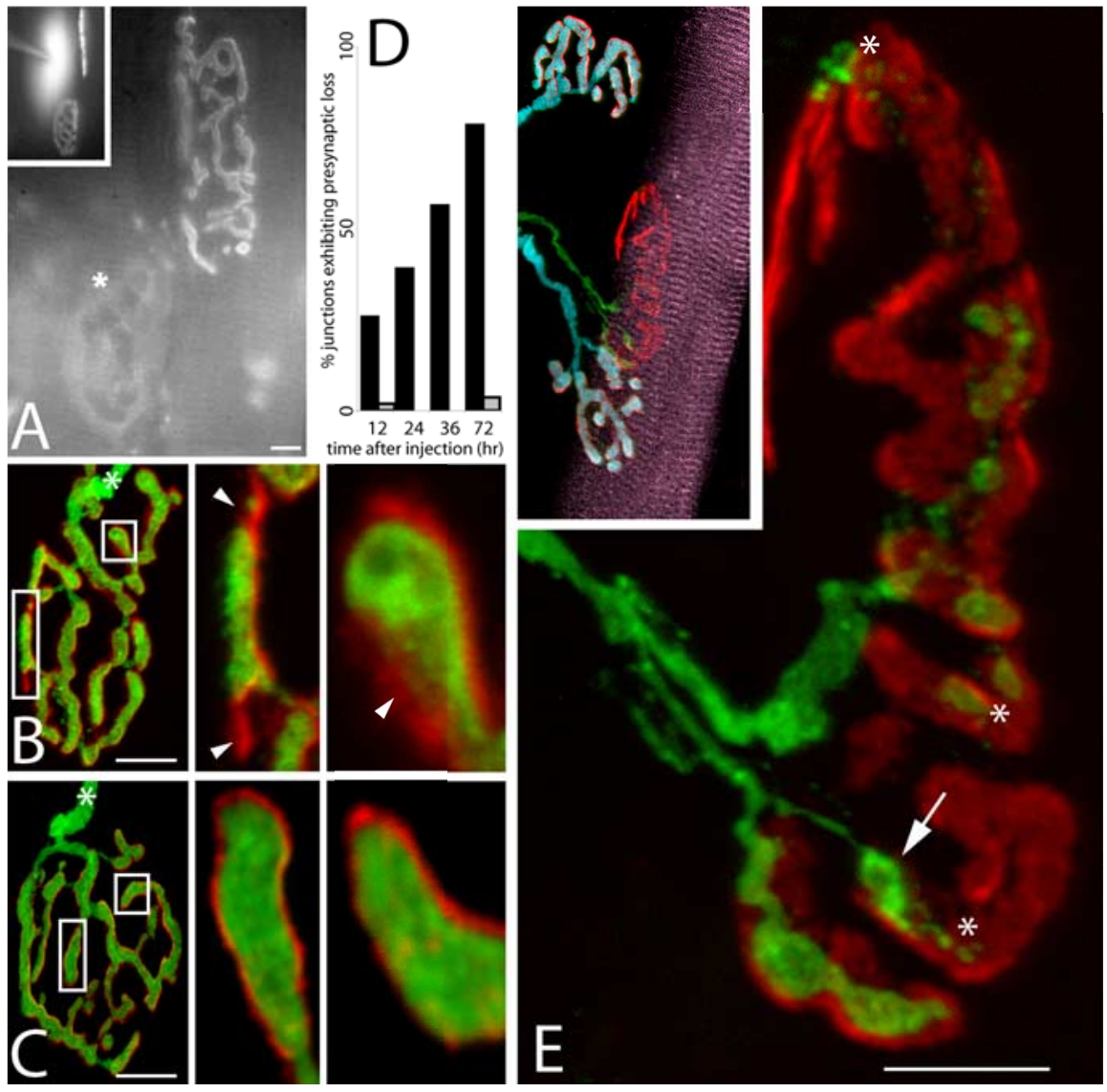

Figure 1. PoPSIn produces rapid synapse elimination. $\boldsymbol{A}$, Inset, Fluorescent injection solution containing a protein synthesis inhibitor is intracellularly injected near the NMJ in a sternomastoid muscle fiber of a living mouse. Three days later, the uninjected fiber (right) showed newly inserted fluorescently labeled AChRs whereas the injected fiber (left) showed a many-fold reduction in new receptor insertion (asterisk). B, C, Twelve hours after PoPSIn, the distal-most portions of YFP-labeled axon terminals (green) no longer occupy postsynaptic sites (red), but control-injected junctions $(\boldsymbol{C}$ ) show complete and normal apposition of presynaptic nerve and postsynaptic AChRs. Asterisks denote the site of nerve entry and arrowheads indicate sites of presynaptic loss. $\boldsymbol{D}$ Histogram showing a progressive increase in the number of NMJs exhibiting presynaptic loss at various times after PoPSIn (black bars), but not in control-injected fibers (gray bars). $\boldsymbol{E}$, Inset, Confocal stack showing the innervation to three muscle fibers, $3 \mathrm{~d}$ after PoPSIn in one fiber (purple). Its axon (green) had become atrophic compared with axons innervating two neighboring muscle fibers (light blue colorized axons). Note, the muscle fiber still contains fluorescent material from the time of injection (purple) showing striations and structurally normal appearance. Most of the nerve terminal has been eliminated from this NMJ. A bulb-like ending (arrow) and shed fluorescent debris (asterisks) are visible. Scale bars: $10 \mu \mathrm{m}$.

somal inactivating protein, either luffin (Kishida et al., 1983) or saporin (Stirpe et al., 1983), near the NMJs of individual sternomastoid muscle fibers in adult mice (Fig. $1 A$, inset). Luffin and saporin irreversibly inactivate ribosomes, but are unable to cross the plasma membrane (Stirpe et al., 1992), preventing nonspecific protein synthesis inhibition in nearby cells (e.g., Schwann cells, axon terminals, or adjacent muscle fibers). The effectiveness and selectivity of protein synthesis inhibition was shown by the lack of new AChR insertion on the injected, but not at neighboring, NMJs (Fig. 1A). Luffin-injected fibers also showed a reduction in dystrophin staining centered at the injection site (supplemental Fig. 1, available at www.jneurosci.org as supplemental material).

\section{Rapid presynaptic retraction after postsynaptic protein synthesis inhibition}

Twelve hours after PoPSIn, we noted presynaptic abnormalities. On some injected muscle fibers $(33 \% ; n=9)$, YFP labeled presynaptic terminal branches were thin and no longer completely occupied the AChR-rich postsynaptic membrane (Fig. $1 B$ ). In- complete presynaptic-postsynaptic apposition was extremely rare in normal muscles $(\sim 3 \% ; n=35)$ (Fig. $1 C)$. Over the next several days, loss of nerve contact with postsynaptic sites progressed (Fig. $1 D)$. In many cases, PoPSIn led to significant denervation of the NMJ (Fig. $1 E$ ). Fibers injected with buffer lacking protein synthesis inhibitor were not significantly different from uninjected fibers (Figs. $1 C, D$, gray bars) and the severity of nerve loss correlated with the magnitude of protein synthesis blockade (supplemental Fig. 2, available at www.jneurosci.org as supplemental material).

Interestingly, we did not find any morphological or physiological signs of protein-synthesis inhibition in muscle fibers at the time presynaptic abnormalities were first observed. Even $3 \mathrm{~d}$ after PoPSIn, when synapse loss was considerable, the injected muscle fibers had a resting potential and could be stimulated to contract by applying exogenous acetylcholine $(n=5$; four mice) (supplemental Fig. 3, available at www.jneurosci.org as supplemental material). By $3 \mathrm{~d}$ after PoPSIn, injected fibers did have fewer total AChRs at their neuromuscular junctions compared with uninjected neighboring fibers $(21.2 \% \pm$ 9.9 decrease; $n=9$ ). This reduction in cell surface AChR number is likely attributable to a lack of significant AChR insertion, as demonstrated in Figure $1 A$. We did not find evidence for significant changes in AChR degradation rates. Nonetheless, these injected fibers remained structurally unaffected: their diameter and sarcomere structure were normal (Fig. $1 E$, inset, supplemental Fig. $3 A$, available at www.jneurosci.org as supplemental material) (diameter, $56.9 \pm 26.9$ $\mu \mathrm{m} ; n=12$ in PoPSIn fibers vs $53.8 \pm 24.3$ $\mu \mathrm{m} ; n=23$ in uninjected fibers). In addition we saw no evidence of leakage of cytoplasmic constituents from the injected fibers (Fig. $1 E$, inset).

Presynaptic retraction after postsynaptic protein synthesis inhibition resembles developmental synapse elimination Of the many cellular programs that have been shown to underlie axonal loss (Bishop et al., 2004; Watts et al., 2004; Kerschensteiner et al., 2005; Portera-Cailliau et al., 2005), axon withdrawal observed after PoPSIn was most similar to the loss that occurs during developmental synapse elimination (Bishop et al., 2004). For example, the earliest presynaptic changes associated with PoPSIn occurred at distal branches within an NMJ (Fig. $1 B$ ). The loss then progressed proximally toward the site of nerve entry to the junction (Figs. $1 E, 2 A$ ). A similar sequence of changes has been described for developmental synapse elimination (Walsh and Lichtman, 2003). The branches that would soon withdraw often terminated in bulb-like structures connected to the axon by thin bridges of cytoplasm (Figs. 1E, $2 B$ ). These bulb-like structures often appeared to have lifted off AChR sites (supplemental 

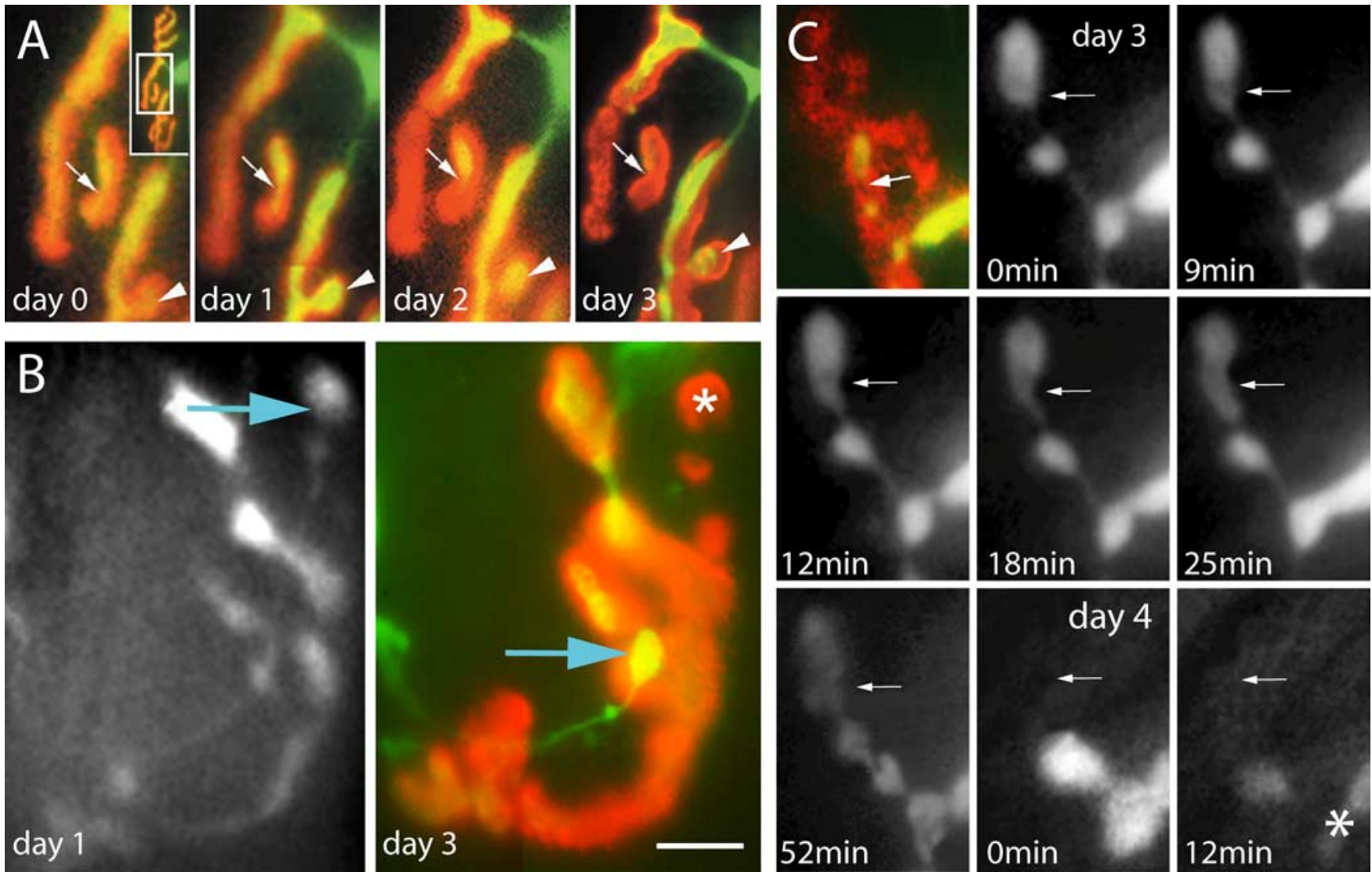

Figure 2. Gradual axon retraction after PoPSIn imaged in vivo. $A$, In this panel of images beginning immediately after PoPSIn, distal presynaptic nerve terminals (inset) progressively withdraw (arrows and arrowheads) from postsynaptic sites (red). B, Time-lapse showing an axonal branch (arrow) eliminated from a synaptic site (asterisk) and, by day 3, becoming a retraction bulb (arrow). C, As an axon retracts, it undergoes rapid fluctuations in caliber (arrows). These fluctuations were followed by axon dimming and disappearance (asterisk). Scale bar, $5 \mu \mathrm{m}$.

Fig. 4, available at www.jneurosci.org as supplemental material), as occurs during development (Gan and Lichtman, 1998). Moreover, as with developmental synapse elimination (Keller-Peck et al., 2001), preterminal axonal branches innervating protein synthesis-blocked muscle fibers became quite thin when synaptic territory was lost (Fig. $1 E$, inset). We also observed fluctuations in the caliber of retracting axonal branches occurring over minutes, which caused the location of varicosities and thin regions to change rapidly (Fig. 2C). Such dynamism is a common feature of retracting axons during development and is thought to be caused by glial interactions with retracting axon branches (Bishop et al., 2004). In addition, dimming and disappearance of fluorescence in presynaptic branches often followed these rapid deformations and, in several instances, debris that contained fluorescent protein remained behind (Fig. $1 E$ ). This phenomenon was reminiscent of axosome shedding observed as retraction bulbs are removed by glia during naturally occurring synapse elimination in early postnatal life (Bishop et al., 2004).

\section{Presynaptic axons vacate postsynaptic AChR sites whereas} Schwann cells remain normal

We were interested to learn whether glial cells mediate axonal retraction after PoPSIn. Some synaptic sites that had completely lost nerve terminals also lacked Schwann cell processes. However, during the early phases of axon-terminal retraction (12-36 h), Schwann cells did not sprout as normally occurs after denervation (Reynolds and Woolf, 1992), but rather remained in synaptic gutters even after axons vacated synaptic territory (Fig. 3, supple- mental Fig. 5, available at www.jneurosci.org as supplemental material). These results argue that glial cells are not intermediaries of the initial phases of nerve loss after PoPSIn. However, rapid changes in axonal morphology were observed several days after PoPSIn, when synaptic contacts are in the final stages of removal (Fig. 2C). These undulations in the caliber of the axon suggest that Schwann cells may be exerting pressure on these axons and, thus, that glial cells play a role in shepherding the eliminated terminals away from the synaptic site.

\section{Discussion}

In sum, we found that interrupting protein synthesis in postsynaptic cells is followed by synaptic deconstruction and axonal withdrawal. We interpret this to mean that we have blocked a previously unappreciated retrograde signaling pathway, which maintains synaptic connections. Moreover, the relatively brief interval between PoPSIn and the onset of nerve terminal withdrawal (12 h) argues that these target-derived signals need to be continuously replenished. We are presently trying to determine the identity of these synaptic maintenance factors. Candidates include trophic factors, protease inhibitors, adhesion molecules, or some combination thereof. The similarity in the appearance of withdrawing axons after PoPSIn and naturally occurring synapse elimination may mean that reduction in some postsynaptic signal instigates synapse removal during normal development. Modulation of such signals, however, could also be a potent mechanism for adult synaptic plasticity or could provide an explanation for circuit changes in aging or disease. 

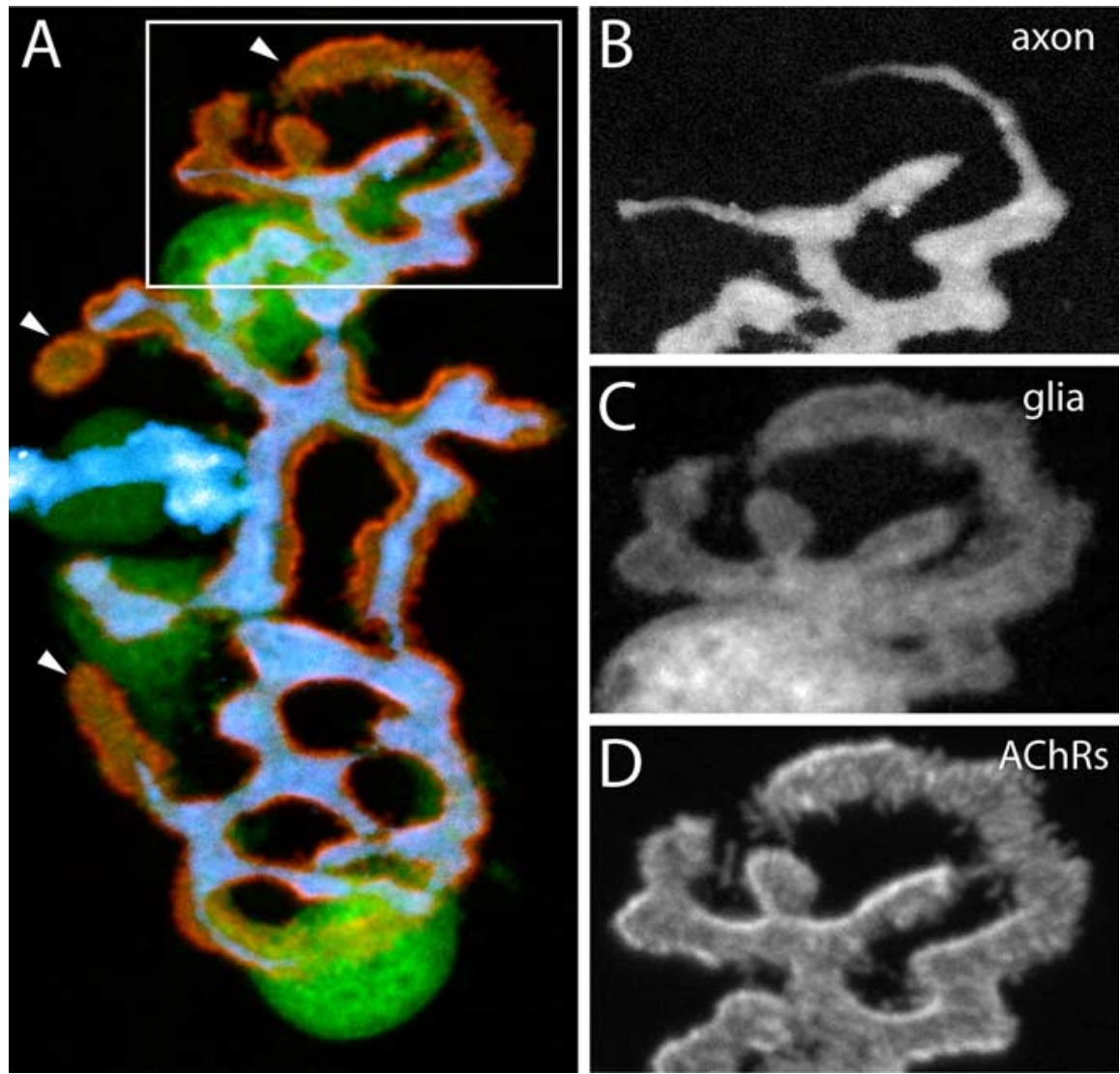

Figure 3. Presynaptic axons vacate postsynaptic AChR sites, whereas Schwann cells remain at those sites. $A$, Thirty-six hours after PoPSIn, terminal axon branches (cyan) show thinning and have retracted from distal regions of synaptic territory (arrowheads). However, terminal Schwann cells (green) are still present and colocalize with BTX-labeled AChRs (red). $\boldsymbol{B}-\boldsymbol{D}$, Singlechannel images from the boxed region in $\boldsymbol{A}$.

\section{References}

Bishop DL, Misgeld T, Walsh MK, Gan WB, Lichtman JW (2004) Axon branch removal at developing synapses by axosome shedding. Neuron 44:651-661.

Culican SM, Nelson CC, Lichtman JW (1998) Axon withdrawal during synapse elimination at the neuromuscular junction is accompanied by disassembly of the postsynaptic specialization and withdrawal of Schwann cell processes. J Neurosci 18:4953-4965.

Feng G, Mellor RH, Bernstein M, Keller-Peck C, Nguyen QT, Wallace M, Nerbonne JM, Lichtman JW, Sanes JR (2000) Imaging neuronal subsets in transgenic mice expressing multiple spectral variants of GFP. Neuron 28:41-51.

Gan WB, Lichtman JW (1998) Synaptic segregation at the developing neuromuscular junction. Science 282:1508-1511.

Keller-Peck CR, Walsh MK, Gan WB, Feng G, Sanes JR, Lichtman JW (2001)
Asynchronous synapse elimination in neonatal motor units: studies using GFP transgenic mice. Neuron 31:381-394.

Kerschensteiner M, Schwab ME, Lichtman JW Misgeld T (2005) In vivo imaging of axonal degeneration and regeneration in the injured spinal cord. Nat Med 11:572-577.

Kishida K, Masuho Y, Hara T (1983) Proteinsynthesis inhibitory protein from seeds of Luffa cylindria roem. FEBS Letters 153:209-212.

Lichtman JW, Magrassi L, Purves D (1987) Visualization of neuromuscular junctions over periods of several months in living mice. J Neurosci 7:1215-1222.

Nguyen QT, Parsadanian AS, Snider WD, Lichtman JW (1998) Hyperinnervation of neuromuscular junctions caused by GDNF overexpression in muscle. Science 279:1725-1729.

Portera-Cailliau C, Weimer RM, De Paola V, Caroni P, Svoboda K (2005) Diverse modes of axon elaboration in the developing neocortex. PLoS Biol 3:e272.

Reynolds ML, Woolf CJ (1992) Terminal Schwann cells elaborate extensive processes following denervation of the motor endplate. J Neurocytol 21:50-66.

Sanes JR, Lichtman JW (2001) Induction, assembly, maturation and maintenance of a postsynaptic apparatus. Nat Rev Neurosci 2:791-805.

Sigrist SJ, Thiel PR, Reiff DF, Lachance PE, Lasko P, Schuster CM (2000) Postsynaptic translation affects the efficacy and morphology of neuromuscular junctions. Nature 405:1062-1065.

Stirpe F, Gasperi-Campani A, Barbieri L, Falasca A, Abbondanza A, Stevens WA (1983) Ribosome-inactivating proteins from the seeds of Saponaria officinalis L. (soapwort), of Agrostemma githago L. (corn cockle) and of Asparagus officinalis L. (asparagus), and from the latex of Hura crepitans L. (sandbox tree). Biochem J 216:617-625.

Stirpe F, Barbieri L, Battelli MG, Soria M, Lappi DA (1992) Ribosome-inactivating proteins from plants: present status and future prospects. Biotechnology (NY) 10:405-412.

Tao HW, Poo M (2001) Retrograde signaling at central synapses. Proc Natl Acad Sci USA 98:11009-11015.

Walsh MK, Lichtman JW (2003) In vivo time-lapse imaging of synaptic takeover associated with naturally occurring synapse elimination. Neuron 37:67-73.

Watts RJ, Schuldiner O, Perrino J, Larsen C, Luo L (2004) Glia engulf degenerating axons during developmental axon pruning. Curr Biol 14:678-684.

Zuo Y, Lubischer JL, Kang H, Tian L, Mikesh M, Marks A, Scofield VL, Maika S, Newman C, Krieg P, Thompson WJ (2004) Fluorescent proteins expressed in mouse transgenic lines mark subsets of glia, neurons, macrophages, and dendritic cells for vital examination. J Neurosci 24:10999_ 11009. 